Original article

\title{
Assessing quality of life and associated factors in post-stroke patients using the world health organization abbreviated generic quality of life questionnaire (WHOQOL-BREF)
}

\author{
Santi Martini ${ }^{\text {a, }}$, Defi Amalia Setia Ningrum ${ }^{\mathrm{b}}$, Khadizah H. Abdul-Mumin ${ }^{\mathrm{c}}$, Chung Yi-Li ${ }^{\mathrm{d}}$ \\ a Division of Epidemiology, Faculty of Public Health, Universitas Airlangga, Indonesia \\ ${ }^{\mathrm{b}}$ FETP Graduate, University of Indonesia, Indonesia \\ ${ }^{\mathrm{c}}$ Institute of Health Sciences (PAPRSB, IHS), Universiti Brunei Darussalam (UBD), Brunei \\ ${ }^{\mathrm{d}}$ Department of Public Health, College of Medicine, National Cheng Kung University, Taiwan
}

\section{A R T I C L E I N F O}

\section{Keywords:}

Educational level

Internal consistency

Post-stroke

Quality of life

WHOQOL-BREF

\begin{abstract}
A B S T R A C T
Introduction: This study piloted the World Health Organization Quality of Life short version form (WHOQOLBREF) to compare the quality of life (QoL) in post-stroke patients who followed the medical stroke rehabilitation program and those whom did not. This study determined which quality of life domains were mostly affected by stroke, and whether there are influencing factors other than rehabilitation.

Methods: A cross-sectional study was conducted at Public Hospital in Surabaya. Patients with stroke less than two years since the first attack were included in this study $(n=52)$. Cronbach's alpha test was performed to assess the internal consistency of WHOQOL-BREF questionnaire. The independent $t$-test and ANOVA were used to compare the differences between patient's characteristics and the six domains of QoL (i.e., perception of QoL, perception of health, physical of health, psychological health, social relationship, and environmental health). Multiple linear regression was performed to assess the influential factors of QoL.

Results: post-stroke patients aged more than 50 years old (76.9\%), male (55.8\%). But, only $48.1 \%$ of those patients participating in medical rehabilitation programs. Age group was significantly associated with QoL in the psychological health domain $(\mathrm{p}=0.021)$; participating in medical stroke rehabilitation programs was significantly associated with social relationship domain $(\mathrm{p}=0.026)$ and the education level was significantly associated to physical health $(\mathrm{p}=0.005)$, psychological heath $(\mathrm{p}=0.035)$ and perception of health $(\mathrm{p}=0.003)$.

Conclusion: Lower education level was significantly associated with a low perception of health, one of QoL domains; and it was the most influential factor of QoL among post-stroke patients.
\end{abstract}

\section{Introduction}

Epidemiological studies evident that approximately 5.5 million people worldwide died annually due to stroke with the estimation that the global prevalence of stroke will gradually increase to as high as $21.9 \%$ by $2030 .^{1,2}$ Stroke is one of the most frequent causes of disability worldwide with 4.4 million disability-adjusted life-years lost. ${ }^{1}$ Most of stroke is ischemic stroke and based on CT scan of ischemic stroke patients, there are 58,6\% subject with lacunar stroke, 20,7\% with large artery atherosclerotic (LAA) stroke, and $20,7 \%$ with cardio-emboli stroke. ${ }^{3}$ The outcome of stroke is often affecting all aspect of individual's life. Motoric function disability is not the only impairment caused by stroke. Beyond those, reduction of social contact, lower self-esteem, and depression after stroke, also contributing factors causing deterioration quality of life. ${ }^{4-6}$ As well, stroke cause depression, the WHOQOL-BREF scores were significantly and persistently lower 1 year after stroke in patients with post-stroke depression. ${ }^{7}$

The management of post-stroke patient is often sequentially complex. Stroke patients have considerably undergone ongoing and changing difficulties related to their disability, their self perception and coping with a new life. ${ }^{8}$ Participation in medical stroke rehabilitation is an important determinant of the adaption process in individuals after stroke. ${ }^{9}$ Medical stroke rehabilitation enables the patients to be less likely to experience worsening functional ability to perform daily

\footnotetext{
* Corresponding author. Division of Epidemiology, Faculty of Public Health, Universitas Airlangga, Kampus C Unair, Surabaya, 60115, East Java, Indonesia.

E-mail addresses: santi-m@fkm.unair.ac.id (S. Martini), defi.amalia@gmail.com (D.A. Setia Ningrum), khadizah.mumin@ubd.edu.bn (K.H. Abdul-Mumin), cyli99@mail.ncku.edu.tw (C. Yi-Li).
} 
activities. ${ }^{10}$ It helps not only to recover physical health but also recover psychosocial aspects.

Measuring the quality of life is the best way to assess the efficacy of intervention such as the medical stroke rehabilitation. ${ }^{11}$ Quality of life among post-stroke patients are lower compared to quality of life before stroke attack and also lower than general population, as shown study in Singapore. One of the widely used tools for assessing quality of life is the World Health Organization Quality of Life (WHO-QOL). The short version of the WHO-QOL is the WHOQOL-BREF. The tool asses quality of life for the general population that focused on individual's perception of their well-being in the domain of perception of quality of life, perception of health, physical health, psychological health, social relationship, environment, and quality of life. ${ }^{12-14}$ The tool is useful in epidemiological studies or clinical trials, as well as to evaluate the effectiveness of treatment and disease control. ${ }^{15}$ All domains of the quality-of-life measurement assessed in this study because we would like to know in which domain the most affected among post stroke patients. In order to prioritize the domains intervened. In other hand, if we didn't measure all aspects of quality of life it can't describe validity of the measurement and as well, the quality of life in a whole.

WHOQOL-BREF had used to measure the quality of life for elderly diabetic patients. WHOOQOL-BREF could measure the quality of intervention programs to increase the quality of life for elderly diabetic. ${ }^{16}$ The WHO-QOL-100 also had conducted to measure quality of life after stroke rehabilitation. ${ }^{17}$ Previous study on WHO-QOL carried on stroke patients to measure the quality of life after visiting Post-stroke clinics and also identify various factors were associated with improving quality of live such as unemployment or reduced income can cause poor quality of life anxiety or depression also cause it. Furthermore, it's very important to identify which factor influencing quality of life. The results become evidence for public health policy.

This study aimed to assess which of domains of quality of life influenced the most among post-stroke patients with use of WHOQOLBREF scale and to investigate the influencing factors to quality of life. As well, to calculate internal consistency of WHOQOL-BREF after translation into Bahasa Indonesia in order to have a valid answer and response among Indonesian people.

\section{Material and methods}

This research was a cross-sectional study using the WHOQOL-BREF scale. Data were collected for two months from January to February 2016 from stroke patients who discharged from one hospital in Surabaya within two years after first stroke attack. This study was approved by the Institutional Health Research Ethics Committee of the primary investigator in Surabaya. All eligible subjects were invited to the study and were adequately acquainted about the purpose and specific details of the study. Only subjects who consented to participate in the research were included in the study.

The population in this study were all stroke patients who discharge from the hospital within two years from the first attack as many as 128 patients. The study included 52 post-stroke patients ( 23 females and 29 males) who had first stroke attack within two years. Selected patient randomly based on the list of the patients from the hospital. These participants were those who did not have cognitive and communication problems. Post-stroke patients had Transient Ischemic Attack (TIA) patients were excluded from the study.

The World Health Organization WHOQOL-BREF questionnaire and those questions divided into six domains were used to assess the quality of life, as the dependent variables. The original version of the questionnaire was provided by the WHO and approved for utilization and translation into Bahasa Indonesia. WHOQOL-BREF consists of 26 questions: two questions assess the domains on perception of quality of life and perception of health of the patients; and the rest of the 24 questions were categorized into another 4 domains: Physical Health with 7 items; psychological health with 6 items; social relationship with 3 items; and environmental health with 8 items. All questions were scored by Likert scale of 5-points. The total score of each domain was calculated according to the scores tables guidelines provided by WHO in the original WHOQOL-BREF. A higher score means a higher quality of life.

Other additional variables collected included gender, age, education level, marital status, and participation in medical stroke rehabilitation programs as independent variables. The age of participants was categorized into two groups: 50 years old and less or over 50 years old. The youngest age was 37 years old and the oldest was 78 years old. The education level was represented by categories into three groups: elementary, secondary, or university. The marital status was categorized into two groups: single or divorced and married. The participation in medical stroke rehabilitation was categorized into two groups: following or not following medical stroke rehabilitation programs.

Statistical analysis was performed using descriptive analysis that included frequencies, percentages, means, and standard deviation (SD). Cronbach's alpha (-C, internal consistency index) was used to estimate the reliability of the WHOQOL-BREF questionnaire in our study sample. The acceptable value of Cronbach's alpha was $0.70<-\mathrm{C}<0.95$. The associations and differences of the patients' characteristics and their QoL was examined and compared by using independent $t$-test and ANOVA. Linear multiple regression analysis was performed to assess the associated factors to quality of life and level of significance was set at $p$ $\leq 0.05$.

\section{Results}

The baseline demographic characteristics of the 52 post-stroke patients are shown in Table 1 . Participants were primarily male $(55.8 \%)$, the mean age of the sample was 58.72 years with range 48.77 till 67.77 years old and dominated by 50 years old group and over (76.9\%). Most of those patients had at least a secondary education level (40.4\%), married $(80.8 \%)$, and had approximately ratio $1: 1$ of those whom followed medical stroke rehabilitation as compared to those whom do not. In this study, Cronbach's alpha value was applied to examine the internal consistency of the WHOQOL-BREF scale (26 items) and the value was 0.797 , which is considered acceptable.

Amongst all the different domains of WHOQOL-BREF, the highest and the lowest mean was found for psychological health (mean $=75.44$ ) and perception of health (mean $=49.03$ ), respectively as seen in Table 2 . It means that post-stroke patients had the best quality of life in psychological health domain. On the other hand, amongst those patients had the lowest of quality of life for perception of health domain. According to age group, there's significant difference in psychological health ( $\mathrm{p}=0.018)$ and social relationship $(\mathrm{p}=0.033)$ between patients of 50 years or less and those aged over 50 years. And the score was higher amongst post-stroke patients aged 50 years or less. For

Table 1

Characteristic of the sample $(n=52)$.

\begin{tabular}{ll}
\hline Characteristic & $\mathrm{n}(\%)$ \\
\hline Age (years) & $58.27 \pm 9.5$ \\
$\leq 50$ & $12(23.1)$ \\
$>50$ & $40(76.9)$ \\
Gender & \\
$\quad$ Male & $29(55.8)$ \\
Female & $23(44.2)$ \\
Education level & \\
Elementary & $15(28.8)$ \\
Secondary & $21(40.4)$ \\
University & $16(30.8)$ \\
Marital status & \\
Single/divorced & $10(19.2)$ \\
Married & $42(80.8)$ \\
Medical rehabilitation & \\
Yes & $25(48.1)$ \\
No & $27(51.9)$ \\
\hline
\end{tabular}


Table 2

Comparison of the WHOQOL-BREF mean scores according to gender, age, education level, marital status, and medical rehabilitation.

\begin{tabular}{|c|c|c|c|c|c|c|}
\hline & \multicolumn{6}{|l|}{ Domain } \\
\hline & $\begin{array}{l}\text { Perception of QOL } \\
\text { Mean } \pm \text { SD }\end{array}$ & $\begin{array}{l}\text { Perception of health } \\
\text { Mean } \pm \text { SD }\end{array}$ & $\begin{array}{l}\text { Physical health } \\
\text { Mean } \pm \text { SD }\end{array}$ & $\begin{array}{l}\text { Psychological health } \\
\text { Mean } \pm \text { SD }\end{array}$ & $\begin{array}{l}\text { Social relationship } \\
\text { Mean } \pm \text { SD }\end{array}$ & $\begin{array}{l}\text { Enviromental health } \\
\text { Mean } \pm \text { SD }\end{array}$ \\
\hline Total & $62.50 \pm 16.789$ & $49.03 \pm 17.823$ & $62.85 \pm 19.031$ & $75.44 \pm 20.165$ & $66.06 \pm 1.311$ & $72.11 \pm 12.607$ \\
\hline \multicolumn{7}{|l|}{ Gender } \\
\hline Male & $62.93 \pm 15.840$ & $52.59 \pm 16.830$ & $62.79 \pm 21.222$ & $76.59 \pm 20.916$ & $65.76 \pm 12.858$ & $73.17 \pm 11.142$ \\
\hline Female & $61.96 \pm 18.262$ & $44.56 \pm 18.397$ & $62.91 \pm 16.320$ & $74.00 \pm 19.544$ & $66.43 \pm 13.720$ & $70.78 \pm 14.390$ \\
\hline $\mathrm{p}$ value & 0.838 & 0.108 & 0.982 & 0.648 & 0.856 & 0.503 \\
\hline \multicolumn{7}{|l|}{ Age (years) } \\
\hline$\leq 50$ & $66.67 \pm 16.283$ & $56.25 \pm 15,539$ & $63.17 \pm 18.473$ & $85.00 \pm 12.778$ & $70.92 \pm 6.127$ & $72.42 \pm 12.479$ \\
\hline$>50$ & $61.25 \pm 16.937$ & $46.87 \pm 18.07$ & $62.75 \pm 19.425$ & $72.57 \pm 21.194$ & $64.60 \pm 14.318$ & $72.025 \pm 12.801$ \\
\hline $\mathrm{p}$ value & 0.332 & 0.111 & 0.947 & $0.018^{*}$ & $0.033^{*}$ & 0.926 \\
\hline \multicolumn{7}{|l|}{ Education level } \\
\hline Elementary & $58.33 \pm 18.094$ & $36.67 \pm 15.100$ & $56.00 \pm 17.708$ & $67.53 \pm 18.909$ & $62.20 \pm 16.772$ & $68.87 \pm 13.400$ \\
\hline Secondary & $60.71 \pm 14.940$ & $51.19 \pm 16.726$ & $64.48 \pm 15.725$ & $79.86 \pm 17.316$ & $66.14 \pm 9.040$ & $73.04 \pm 10.500$ \\
\hline University & $68.75 \pm 17.078$ & $57.81 \pm 15.052$ & $67.12 \pm 23.215$ & $77.06 \pm 23.589$ & $69.56 \pm 13.623$ & $73.94 \pm 14.507$ \\
\hline $\mathrm{p}$ value & 0186 & $0.002^{*}$ & 0.238 & 0.183 & 0.301 & 0.494 \\
\hline \multicolumn{7}{|l|}{ Marital status } \\
\hline $\begin{array}{l}\text { Single/ } \\
\text { divorced }\end{array}$ & $61.31 \pm 16.750$ & $50.00 \pm 18.313$ & $62.88 \pm 19.215$ & $76.43 \pm 19.067$ & $66.59 \pm 12.172$ & $71.714 \pm 12.377$ \\
\hline Married & $67.50 \pm 16.874$ & $45.00 \pm 15.811$ & $62.70 \pm 19.241$ & $71.30 \pm 24.989$ & $71.71 \pm 12.377$ & $73.800 \pm 14.101$ \\
\hline $\mathrm{p}$ value & 0.299 & 0.431 & 0.979 & 0.475 & 0.550 & 0.643 \\
\hline \multicolumn{7}{|c|}{ Medical Stroke rehabilitation } \\
\hline Yes & $60.18 \pm 14.310$ & $44.44 \pm 14.434$ & $67.88 \pm 17.871$ & $79.60 \pm 20.279$ & $69.80 \pm 11.965$ & $74.36 \pm 13.801$ \\
\hline No & $65.00 \pm 19.094$ & $54.00 \pm 20.000$ & $58.19 \pm 19.201$ & $71.59 \pm 19.647$ & $62.59 \pm 113.397$ & $70.037 \pm 11.250$ \\
\hline $\mathrm{p}$ value & 0.306 & 0.52 & 0.66 & 0.154 & $0.047^{*}$ & 0.220 \\
\hline
\end{tabular}

$\mathrm{QOL}=$ Quality of life, $\mathrm{SD}=$ Standard deviations, *The mean difference is significant at $\leq 0.05$ level.

educational level, there's significant difference for quality of life in domain of perception of health $(\mathrm{p}=0.002)$. The highest score was 67.12 for post-stroke patients who graduated from University. For following medical rehabilitation, it's found significant difference in the domain of social relationship $(\mathrm{p}=0.047)$ and the score for post-stroke patients who followed medical rehabilitation was higher than those patients who did not follow any medical rehabilitation programs, namely 69.80 and 62.59 respectively (Table 2). There's no significant difference in quality of life between patients with different marital status.

Fig. 1 illustrated the comparison of the quality of life between the group of patients who followed medical stroke rehabilitation with those who did not. The results indicated that patients whom followed medical stroke rehabilitation scored higher than the group of patients whom did not. The results also showed that the group of patients who followed medical stroke rehabilitation scored higher in all the four domains of the questionnaire, as well as two additional domains of general quality of life. The highest domain score was psychological health which was evident in those patients whom followed medical stroke rehabilitation.

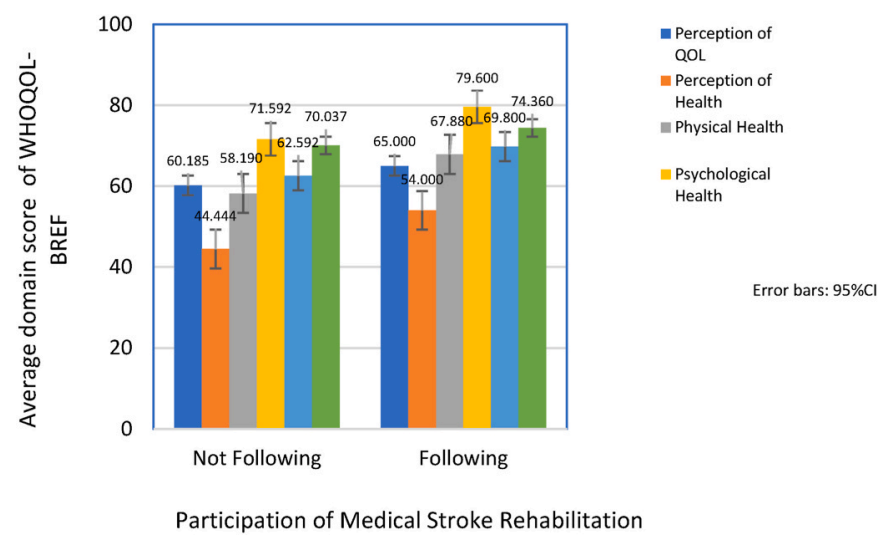

Fig. 1. Bar chart demonstrating the influence of medical stroke rehabilitation on QoL. Patients were divided into two groups based on whether they participate or not in the medical stroke rehabilitation. The bar shows average domain score of WHOQOL-BREF.
But, the highest deviation domain score between the two groups was physical health score, with 9.69 deviation score.

Cronbach alpha coefficient was performed to examine internal consistency of all of the questions in the WHOQOL-BREF (26 items) and all domains of the questionnaire. The Cronbach alpha coefficient of WHOQOL-BREF was in the range of acceptable value, it's 0.791. Cronbach alpha analysis of each domain indicated the following values: physical health domain (0.747), psychological health domain (0.744), social relationship domain $(0.466)$ and environmental health domain (0.401).

Table 3 illustrates the results of Backward Multiple Linear Regression. It's found that psychological health domain of QoL was significantly associated to both age group $(\mathrm{p}=0.021)$ and education level $(\mathrm{p}=$ 0.035). Physical health domain of QoL was also significantly associated to education level $(\mathrm{p}=0.005)$. Similarly, perception of health of QoL was associated to education level $(p=0.003)$. For another domain, social relationship was associated to participation of medical rehabilitation $(\mathrm{p}=0.026)$.

\section{Discussion}

One of the objectives of this study was to evaluate the internal consistency (reliability) of WHOQOL-BREF questionnaire in post-stroke patients. Reliability analysis in this study indicated an acceptable internal consistency of WHOQOL-BREF scale $(\alpha=0.791)$ and for each of its domains were high, except for social relationships domain that is partly low $(\alpha=0.466)$ and environmental health domain $(\alpha=0.401)$. Using the same instrument, Lee et al., investigated validation WHOQOLBREF in patients with stroke and spinal cord injury. In this study, the value of Cronbach's alpha ranged from 0.603 to 0.875 , values that are higher than the present study. Lower internal consistency in social relationships domain can be caused by the small number of questions ( 3 items). ${ }^{18}$

Meanwhile, the other objectives of this study were to evaluate the quality of life in patients two years after stroke and to determine which of these factors influence QOL most. Using the WHOQOL-BREFF tool, we can observe that in the four main domains, the highest mean satisfaction rating was found for psychological health (mean $=75.44$ ), implying good self-esteem, spiritually, cognition, and positive feeling. Moreover, 
Table 3

Backward multiple linear regression analyses of significant factors associated with QOL.

\begin{tabular}{|c|c|c|c|c|c|c|}
\hline \multirow[t]{2}{*}{ QOL domains } & \multirow[t]{2}{*}{ Variables } & \multicolumn{2}{|c|}{ Unstandardized Coefficients } & \multirow{2}{*}{$\frac{\text { Standardized Coefficients }}{\text { Beta }}$} & \multirow[t]{2}{*}{$\mathrm{t}$} & \multirow[t]{2}{*}{$P$ value } \\
\hline & & B & SE & & & \\
\hline Physical Health & Education level & 0.806 & 0.276 & 0.382 & 0.923 & 0.005 \\
\hline \multirow[t]{2}{*}{ Psychological Health } & Education level & 0.651 & 0.300 & 0.288 & 0.175 & 0.035 \\
\hline & Age Category & -1.973 & 0.826 & -0.415 & -0.388 & 0.021 \\
\hline Social Relationship & Participation of Medical Rehabilitation Program & 1.229 & 0.536 & 0.306 & 0.294 & 0.026 \\
\hline Environmental Health & None & - & - & - & - & - \\
\hline Perception of Health & Education level & 0.218 & 0.071 & 0.399 & 0.080 & 0.003 \\
\hline
\end{tabular}

$\mathrm{QOL}=$ Quality of life.

the lowest mean satisfaction was showed for physical health (mean = 62.85), indicating not very good activity of daily living, dependence on medication and medicinal aids, less energy and fatigue, pain and discomfort. $^{14}$

In some cases, the coefficient of correlation is not statistically significant when comparing the WHOQOL-BREF mean score between patient's characteristic and their QOL. The results indicated a significance association between the mean score of social relationship and psychological health in patients which was evidently higher score among patients who aged 50 years old and less than those who aged over 50 years old. The results of this study are consistent with the results of the study by Deborah et al. and Celeb et al. Increasing age of post-stroke patients was followed by a decrease in the total score of quality of life, which can be interpreted as low quality of life. ${ }^{6,19}$ The finding also showed that every one year increase in age causing a decrease in the score of quality of life by $0.226 .{ }^{20}$ Older post-stroke patients are more at risk of having depression and anterior circulation stroke. ${ }^{7,21}$ Indeed, depression has long been the most common psychological disorder reported in stroke survivors, and might affect physiological defects. ${ }^{22}$

The mean score also showed that the social health of patients whom followed medical stroke rehabilitation was significantly better than those whom do not. This is echoed in research conducted by Rice et al. where there were significant improvements in physical function, mobility, and confidence in post-stroke patients who attended medical rehabilitation. ${ }^{23}$ It was consistent with this study as seen in Fig. 1 . There are some significant association amongst post-stroke patient whom followed medical stroke rehabilitation with better quality of life in all WHOQOL-BREF domains. The most significant results was "social relations", which refers to intimate emotional interactions and a sense of social support, for example, from family or friends. ${ }^{24}$ Medical stroke rehabilitation were evident to be a means of post-stroke patients to connect with others who had the same disabilities. Group exercises may be more effective and enjoyable. A local pilot study showed that group exercises supervised by a physiotherapist in a social center setting were effective in improving social relation, mobility and stability in elderly people who had been chronically disabled by stroke. ${ }^{25}$

The results of multiple linear regression found that education level was an associated factor affecting perception of health, physical health, and psychological health. The existing knowledge often highlighted health disparities. ${ }^{26,27}$ The level of education is a condition that influences a person to accept or reject new knowledge that they received. Hence, a person whom have adequate educational background is likely to be positively influence in their behavior in seeking care and treatment of a disease, as well as to decide action to be and should be taken in order to treat their health problems. Patients whom have higher level of education had higher quality of life status. This is related to their positive level of adequacy of knowledge to understand and comply with doctor's suggestions related to improving their quality of life $\mathrm{e}^{28}$

\subsection{Study strengths and limitations}

Result of this study identified limitations of the National Institutes of Health Stroke Scale (NIHSS) and Back Depression Inventory (BDI) which were developed in the United States of America (US), particularly in terms of clinical factors measure of stroke such as stroke severity. Other areas also may need exploration to better explain factors affecting poststroke QOL.

However, this study evidence that the translated version of the WHOQOL-BREF into Bahasa Indonesia is found to be cross-culturally adaptable and is useable in Indonesia. It has potential to be used in the Asian and Asia Pacific region that used Bahasa Indonesia as the mode of communication. WHOQOL-BREF can be safely and effectively applied to post-stroke patients. Older post-stroke patients have been associated with negative psychological and social relationships. Yet, the findings of this study emphasize the impact of medical stroke rehabilitation which is evident to increase all WHOQOL-BREF domains score, in comparison with post-stroke patients whom do not follow such rehabilitation.

\section{Conclusion}

The most associated factor for quality of life based on WHOQOLBREF among post sroke patients was education level. Higher of education level cause increased score for quality of life in domain of physical health, psychological health, and perception of health. It means high education level cause good quality of life. Those patients aged 50 years old or younger was associated with good quality of life mainly psychological health domain. Participating in medical stroke rehabilitation program was associated with social relationship domain of quality of life. Internal consistency was good and adequate for all 26 questions of WHOQOL-BREF, its value was 0.791 .

Education, specifically in terms of knowledge about medical stroke rehabilitation is identified as one of the most associated factors for quality of life amongst post-stroke patient. This study highlights the importance of improving communication and provision of information concerning the benefits of medical stroke rehabilitation, which consequently, facilitate improvement of the quality of life of post-stroke patients. Structured planning of post-stroke rehabilitation programs and discharge preparation needs also be taken into consideration.

\section{Declaration of competing interest}

All Author declare there is no conflict of Interest.

This study was approved by the Institutional Health Research Ethics Committee of the primary investigator in Surabaya.

\section{Acknowledgements}

Faculty of Public Health Universitas Airlangga.

\section{References}

1 Mukherjee D, Patil CG. Epidemiology and the global burden of stroke. World neurosurgery. 2011;76(6):S85-S90.

2 Go AS, Mozaffarian D, Roger VI, et al. Heart disease and stroke Statistics-2013 update: a report from the American heart association. Circulation. J Am Heart Assoc. $2020 ; 129$.

3 Amalia L, Furqani MA, Parwati I, Rizal A, Panigoro R. Correlation between Alberta stroke programme early computed tomography score (ASPECTS) and National 
Institute of health stroke score (NIHSS) in ischemic stroke. Sains Malays. 2020;49(5): $1115-1120$.

4 Marchant NL, Reed BR, Sanossian N, et al. The aging brain and cognition: contribution of vascular injury and a $\beta$ to mild cognitive dysfunction. JAMA Neurol. 2013;70(4):488-495. Apr 1.

5 Dabrowska-Bender Marta, Milewska Magdalena, Golabek Aleksandra, DudaZalewska Aneta, Anna Staniszewska. The impact of ischemic cerebral stroke on the quality of life of patients based on clinical, social, and psychoemotional factors. J Stroke Cerebrovasc Dis. 2017;26:101-107.

6 De Wit L, Theuns P, Dejaeger E, et al. Long-term impact of stroke on patients' healthrelated quality of life. Disabil Rehabil. 2017;39(14):1435-1440. Jul 3.

7 Kim E-S, Kim J-W, Kang H-J, et al. Longitudinal impact of depression on quality of life in stroke patients. Psychiatry Investig. 2018;15(2):141-146.

8 Allesen H. Body, Coping and Self-Identity. A Qualitative 5-year Follow-Up Study of Stroke. Disabil Rehabil [serial on i2014. 2015. https://doi.org/10.3109/ 09638288.2013.788217. Available from.

9 Brands IM, Wade DT, Stapert SZ, van Heugten CM. The adaptation process following acute onset disability: an interactive two dimensional approach applied to acquired brain injury. Clin Rehabil. 2012;26:840-852.

10 Chen Y, Abel KT, Janecek JT, Chen Y, Zheng K, Cramer SC. Home-based technologies for stroke rehabilitation: a systematic review. Int J Med Inf. 2019;123:11-22. Mar 1.

11 Schindel D, Schneider A, Grittner U, Jöbges M, Schenk L. Quality of life after stroke rehabilitation discharge: a 12-month longitudinal study. Disabil Rehabil. 2021;43 (16):2332-2341. Jul 31.

12 Purba FD, Hunfeld JA, Iskandarsyah A, et al. Quality of life of the Indonesian genera population: test-retest reliability and population norms of the EQ-5D-5L and WHOQOL-BREF. PLoS One. 2018;13(5), e0197098. May 11.

13 Reba K, Birhane BW, Gutema H. Validity and reliability of the Amharic version of the World Health Organization's quality of life questionnaire (WHOQOL-BREF) in patients with diagnosed type 2 diabetes in Felege Hiwot referral hospital, Ethiopia. J Diabetes Res. 2019. May 6;2019, 6 pages.

14 Ilić I, Šipetić-Grujičić S, Grujičić J, Živanović Mačužić I, Kocić S, Ilić M. Psychometric properties of the world health organization's quality of life (WHOQOL-BREF) questionnaire in medical students. Medicina. 2019;55(12):772. Dec.

15 Pinto JM, Arenillas JI, Martín Nogueras AM, Ramos González J, Gómez Gómez FP. The quality of life of asthmatic patients evaluated by the WHOQOL-BREF and the SGRQ. Fisioterapia (Madr). 2010;32:116-122.
16 Jahromi MK, Ramezanli S, Taheri L. Effectiveness of diabetes self-management education on quality of life in diabetic elderly females. Global J Health Sci. 2015;(1): 10. Jan 7.

17 Giaquinto S, Giachetti I, Spiridigliozzi C, Nolfe G. Quality of life after stroke in a rehabilitation setting. Clin Exp Hypertens. 2010;32(7):426-430. Nov 1.

$18 \mathrm{Ju}$ Lee Kuem, Jan Hye In, Choi Hyun. Korean translation and validation of the WHOQOL-DIS for people with spinal cord injury and stroke. Disabil.Health J. 2017; $30: 1-5$.

19 Celeb AG, Aderonke O, Akinpelu. Quality of life of nigerian stroke survivors during first 12 months post-stroke. Hong Kong Physiother J. 2012;30:18-24.

20 She R, Yan Z, Hao Y, et al. Health-related quality of life after first-ever acute ischemic stroke: associations with cardiovascular health metrics. Qual Life Res. 2021;(May 1), 1-1.

21 Theeke Laurie, Lucke-Wold A Noelle, Mallow Jennifer, Horstman Patricia. Life after stroke in appalacia. Int J Nurs Sci. 2017;4:105-111.

22 Kim ES, Kim JW, Kang HJ, et al. Longitudinal impact of depression on quality of life in stroke patients. Psychiatry investigation. Feb. 2018;15(2):141.

23 Rice D, Janzen S, Mcintyre A, Vermeer J, Britt E, Teasell R. Comprehensive outpatient rehabilitation program: hospital-based stroke patient rehabilitation. J Stroke Cerebrovasc Dis. 2016;25(5):1158-1164.

24 Dabrowska-Bender Marta, Milewska Magdalena, Golabek Aleksandra, DudaZalewska Aneta, Anna Staniszewska. The impact of ischemic cerebral stroke on the quality of life of patients based on clinical, social, and psychoemotional factors. J Stroke Cerebrovasc Dis. 2017;26:101-107.

25 Sarfo FS, Adamu S, Awuah D, Sarfo-Kantanka O, Ovbiagele B. Potential role of telerehabilitation to address barriers to implementation of physical therapy among West African stroke survivors: a cross-sectional survey. J Neurol Sci. 2017;381:203-208. Oct 15.

26 Odonkor CA, Esparza R, Flores LE, et al. Disparities in health Care for Black Patients in physical medicine and rehabilitation in the United States: a narrative review. PM\&R. Feb. 2021;13(2):180-203.

27 Chuluunbaatar E, Chou Y-J, Pu C. Quality of life of stroke survivors and their informal caregivers: a prospective study. Disabil.Health J. 2016;9:306-312.

28 Pakpahan M, Siregar D, Susilawaty A, et al. Promosi Kesehatan Dan Perilaku Kesehatan. Yayasan Kita Menulis; 2021. Feb 19. 